\title{
Promoting Public Health Workforce Training for Developing and Transitional Countries: Fifty-Year Experience of the Braun School of Public Health and Community Medicine, Jerusalem, Israel
}

\author{
Yehuda Neumark, PhD, ${ }^{1}$ \\ Orly Manor, PhD, ${ }^{1}$ \\ Elliot M Berry, MD, $\mathrm{PhD}^{1}$
}

\begin{abstract}
The goal and responsibility of graduate institutions of public health is to educate and train the public health workforce to address the challenges of Health for All in the 21 st century and meet the Millennium Development Goals. Over the past 50 years, the Braun School of Public Health and Community Medicine in Jerusalem, Israel-through its international training activities including the International Master of Public Health (IMPH) program, PhD training, and short-term training workshops in Israel and abroad-has built a network of public health scholars in low-, transition- and high-income countries who benefit from academic expertise in Israel and transfer that expertise towards development efforts in their home communities. Given the number of IMPH graduates, the countries they come from, and the work they do upon their return, the IMPH has had real and sustainable impact on public health globally and in developing countries in particular.
\end{abstract}

Key Words: International health, public health education, MPH, developing countries, transitional countries, Israel.

Recommended citation: Neumark Y, Manor O, Berry EM. Promoting Public Health Workforce Training for Developing and Transitional Countries: Fifty-Year Experience of the Braun School of Public Health and Community Medicine, Jerusalem, Israel. Public Health Reviews. 2011;33:251-63.

\footnotetext{
${ }^{1}$ Braun School of Public Health and Community Medicine, Hebrew University-Hadassah, Jerusalem, Israel.
}

Corresponding Author Contact Information: Dr. Yehuda Neumark at yehudan @ekmd.huji. ac.il; Director, International MPH Program, Braun School of Public Health, HebrewUniversity-Hadassah, P.O. Box 12272 Jerusalem, Israel 91120. 


\section{INTRODUCTION}

The Millennium Development Goals, adopted by all United Nations member states, aim to promote health through eradication of hunger and poverty, reduction in child mortality and improvements in maternal health, and the fight against HIV/AIDS, malaria and other endemic diseases. ${ }^{1}$ These goals can only be realized through public health actions and services that will prevent epidemics and the spread of disease, protect the public against environmental hazards and injuries, promote healthy behaviors, respond to disasters and assist communities in recovery, and assure accessible quality health services. Yet there is a growing shortage of trained public health practitioners, not only in developing regions of the world but also in developed countries.

To meet the challenges of Health for All in the $21^{\text {st }}$ century, a welltrained and motivated health workforce that is oriented to meet the needs of the communities is essential for local and national health systems to function properly. Public health practitioners must also assume a role in narrowing health disparities between and among nations, communities, and neighborhoods. ${ }^{2}$

To ensure the delivery of essential services, the professional public health workforce requires up-to-date theoretical knowledge and practical skills in a broad range of core competencies, in light of the continuous evolution of the public health field. ${ }^{3}$ It is the goal of graduate institutions of public health to educate and train the public health workforce, ${ }^{4}$ and to strive to meet the motto of the Association of Schools of Public Health in the European Region (ASPHER) of "strengthening public health by improving education and training of public health professionals for both practice and research" (www.aspher.org).

\section{BRAUN SCHOOL OF PUBLIC HEALTH AND COMMUNITY MEDICINE}

The Braun School of Public Health \& Community Medicine, and its International Master of Public Health (IMPH) Program strive to improve the physical, mental and social welfare of the global community, with a commitment towards excellence in interdisciplinary training and research. As the first and largest school of public health in Israel, The Braun School has 50 years experience in training health and other professionals from Israel and around the globe. In recognition of our ongoing public health training efforts in Israel and abroad, the World Health Organization 
designated our School as a WHO Collaborating Centre for Capacity Building in Public Health in 2007.

From the early 1960s onwards, our Israeli Master of Public Health (MPH) course has had a major impact on the training and function of public health and health care professionals within Israel, including the overwhelming majority of the senior public health personnel of the country who hold our MPH degree.

The IMPH Program was established in 1970 in order to fulfill the School's mission and share our learned experiences and expertise with health professionals from developing countries. The IMPH Program is scientifically stimulating and culturally rewarding, allowing study and interaction with peers from different professional and cultural backgrounds, in the unique setting of Jerusalem. The current IMPH class, for example, includes 20 trainees from countries with life expectancy among the lowest in the world (e.g., Nigeria - 47.4 years) to the highest (e.g., Canada - 80.3 years).

For the past 40 years, our IMPH students have benefited from the foresight of the School founders who in the late 1960s established the School's academic philosophy which dictated the development of integrated training in research methodology with the study of major public health issues, and their application in public health practice in the students' home communities. As Kahn and Tollman suggested, "An education curriculum is a delicate plant; it will thrive only with constant attention, proper nourishment and periodic trimming and shaping", and so, although the broad educational and professional similarities have been retained over the past four decades, we regularly review the details of our curriculum and the specific courses to ensure its relevancy and timeliness (e.g., health system reforms, community mental health, HIV/AIDS). The IMPH curriculum (Table 1) comprehensively addresses the public health core competencies currently specified by ASPHER ${ }^{6}$ and by the American Association of Schools of Public Health (ASPH) ${ }^{7,8}$ to equip public health graduates for the tasks necessary to meet the Millennium Development Goals.

This multidisciplinary and interdisciplinary approach toward public health education, guides the School's teachers, researchers and students to holistically examine health and social issues that arise at the individual level, and are woven together into a familial, social and environmental web, even before health becomes a 'problem'.

Our program combines academic excellence with practical tools and strategies for identifying and characterizing public health challenges and formulating relevant responses at the institutional, community, and national 
level in the students' own countries. ${ }^{8}$ Our students are therefore encouraged to work on data from their own communities and incorporate their own experiences into their academic work. One opportunity for this is the mentored thesis or master paper (which is less extensive in scope than a thesis, and is supplemented with additional course work) that all students undertake. Each student receives personal guidance in deciding which track is most suitable for him or her.

\section{Table 1}

Core curriculum of the International MPH, at Hebrew University-Hadassah in Jerusalem, Israel

\section{Community Oriented Primary Health Care (COPC) Workshop}

Control of Communicable Diseases

Descriptive Statistics in Public Health

Environmental \& Occupational Health

Health Behavior

Health Economics

Interpretation of Epidemiological Data

Introduction to Public Health

Introduction to Public Health Nutrition

Organization of Medical Care

Principles and Uses of Epidemiology

Public Health Practice, Organization \& Evaluation

Public Health Seminar

Qualitative Methods in Health and Public Health

Sociological Aspects of Health and Disease

Statistical Inference in Public Health

Statistical Package for the Social Sciences (SPSS)

Survey and Research Methods

Reforms in Health Care Systems

Research Forum

At the end of each semester, students complete an anonymous online evaluation of all courses and teachers. In addition, upon fulfillment of all academic requirements, students are asked to complete a summative evaluation of the entire IMPH training experience. Results of these evaluations are used to guide curriculum development and program improvement. 


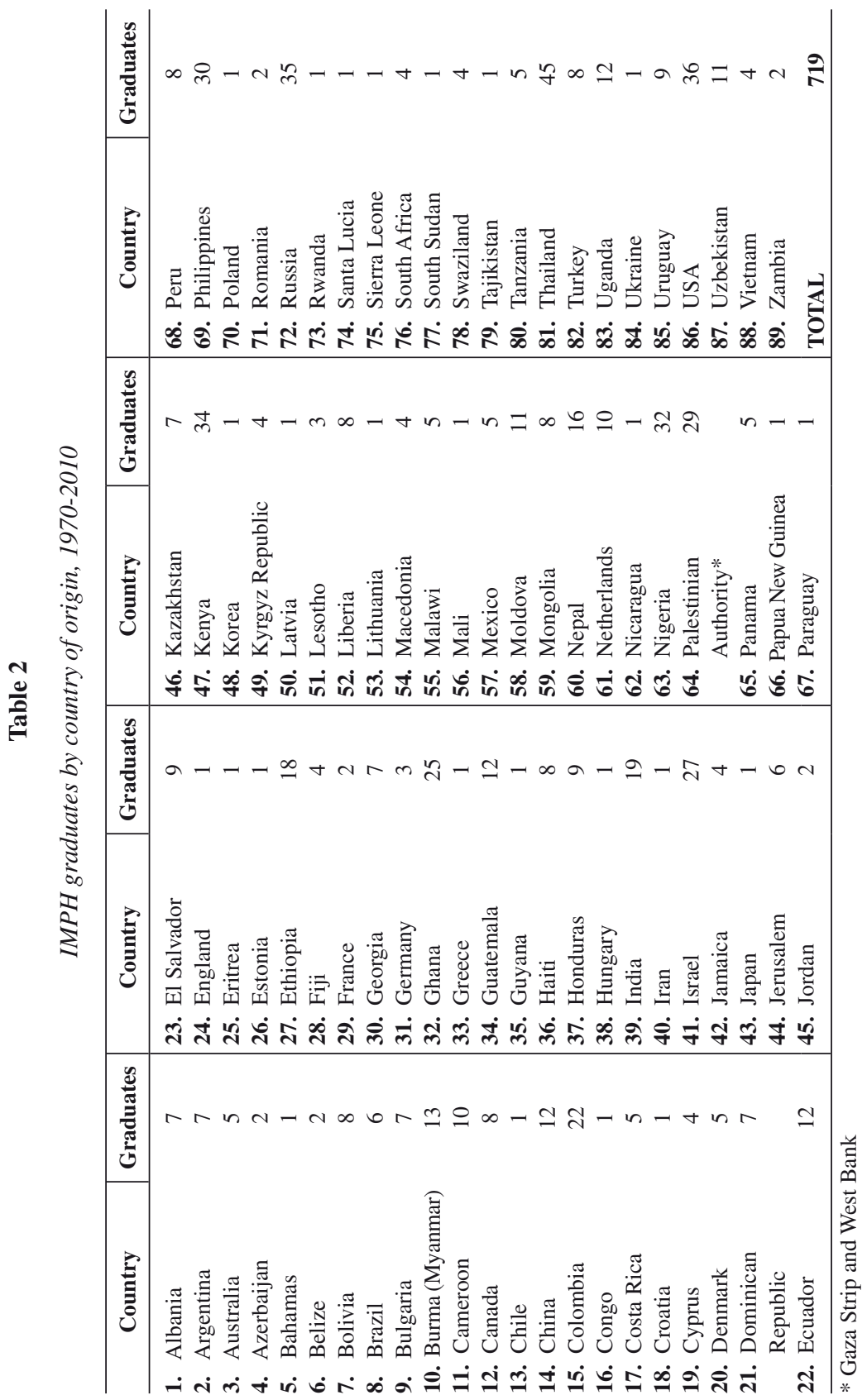


The comprehensive IMPH training experience has prepared our more than 700 graduates from 90 countries in developing and transition regions, as well as developed countries of North America and Western Europe (Table 2), to assume key positions as public health leaders and teachers in their home countries. IMPH alumni can be found in academia in leading universities worldwide, government service at all levels including federal ministers of health, in the non-governmental sector nationally and internationally, in clinical practice, and industry.

The IMPH curriculum maintains a relatively strong focus on quantitative thinking and skill development as sound public health decision-making and practice requires carefully collected, analyzed and interpreted information. ${ }^{9-12}$

A rather unique element of the IMPH Program continues to be the Community Oriented Primary Care (COPC) Workshop..$^{13-14}$ The COPC model represents an innovative approach to health care delivery at the population level through the integration of clinical medicine and public health, and entails a detailed assessment of a community's specific health needs, determination of priorities, and development of feasible and affordable intervention programs. This allows scarce resources to be targeted to high priority health care needs, extends health promotion outward from the medical clinic or hospital into the community, and can serve to reduce barriers between health care providers and community residents through the involvement and participation of the community in designing and implementing disease-prevention and health-promotion interventions. ${ }^{15}$ The relevancy of the COPC Workshop is enhanced by relying on data and information provided by the participants about communities that they are familiar with and have worked in. Evaluations of the Workshop by IMPH graduates (3 to 5 years after completing the program) revealed that more than half are actively involved in the application of COPC principles and methods. As one IMPH alumnus commented: "The Community Oriented Primary Care (COPC) program of the School is emerging as the cornerstone of public health education, health planning and community organization for many developing countries. COPC graduates represent the finest example of Israel's contribution to global development". The COPC model is based on principles of social medicine practiced by Sidney and Emily Kark (the Braun School founders) in rural South Africa in the mid-20th century and brought by them to Israel, where it was further developed, applied and evaluated for over three decades in the Hadassah Community Health Center in Jerusalem. The Center's international COPC involvement has influenced primary health care policy both in Israel and 
worldwide, and set the stage for the development of collaborative links with academic and clinical institutions in countries around the world. We have also taken the model back to its country of origin - South Africa, and to numerous sites throughout Western and Eastern Europe, North America and Latin America, where COPC training workshops have been conducted.

From Israel's earliest years of statehood, the country's policy-makers were moved by a compelling desire to share the knowledge gained from Israel's own development experience. Israel's first Prime Minister - Mr. David Ben Gurion, believed that the nation's historic message was to give support to developing countries striving to advance in technological and socio-economic fields. This national aspiration was strengthened by Mrs. Golda Meir (Prime Minister from 1969 until 1974) who considered it Israel's duty to participate in the great venture of development cooperation. Her personal commitment to international cooperation led to the founding of the Israel Center for International Cooperation and Development (MASHAV) of the Israeli Ministry of Foreign Affairs to bring Israel's technological, medical and educational advancements to the developing world. These efforts gave expression to the very traditions and values upon which Israel was established.

It was through the generous support of MASHAV that the IMPH Program was established. To facilitate this technology- and knowledgesharing initiative, all students from developing and transition regions are accepted into the program with a scholarship that covers virtually all expenses associated with studying and living in Israel. Over the years, these scholarships have been made available through the funding of MASHAV, the Open Society Institute (Soros Foundation, New York), and later the Legacy Heritage Fund Ltd. Today, scholarship funding is generously provided by the Pears Foundation, together with continuous substantial support from the Hadassah Medical Organization, and the Hebrew University of Jerusalem and its American and British Friends associations.

Given the number of IMPH graduates, the countries they come from (Table 2), and the work they do upon their return, the IMPH has had real and sustainable impact on public health globally and in developing countries in particular. One example of such a contribution is a comprehensive cholera prevention program that was developed by students of the 2007/2008 Hebrew University-Hadassah Legacy-Heritage International Masters of Public Health Program as a class project. The program aims to increase safe drinking water sources; promote awareness in the community about cholera prevention; improve surveillance and reporting of cholera cases; build a centralized network for monitoring and immediate appropriate 
action; mobilize rapid response teams to areas of suspected cholera cases; improve management of patients; prevent the spread of the disease; and post-epidemic investigation and education. The program was utilized by the Kenyan Red Cross in displaced persons camps during the political crisis in Kenya, and has been adopted by the International Committee of the Red Cross (ICRC) and the International Federation of Red Cross and Red Crescent Movement (IFRC) for implementation beyond the camps.

\section{ALUMNI}

Upon graduation, IMPH students join a global community of more than 1500 similarly trained public health professionals in Israel ( 800 students have graduated from our Israeli MPH Program) and worldwide. By capitalizing on these potential connections, alumni are able to forge relationships that could open up career opportunities and contacts with like-minded professionals, as well as form new friendships and build invaluable social networks.

As comprehensive and intense as the IMPH training experience may be, we realize that "formal education in public health is not a vaccine that will prevent ignorance and ineffectiveness later in one's career". ${ }^{16}$ To this end, we maintain active communication with hundreds of our alumni globally on a regular basis and encourage the development of professional links between IMPH alumni and one another and with the Braun School. When possible we invite IMPH alumni back to Israel for continuing education workshops. In 2000, we organized such a workshop for some 70 alumni from around the globe and across the years, to enhance knowledge, confidence, and competence in developing research, teaching and health promotion activities in their home countries. More recently, with the generous support of the Pears Foundation, the School organized a ten-day continuing education workshop in Jerusalem in 2010 to provide IMPH Alumni with up-to-date skills and knowledge in a broad range of topics through formal lectures, seminars and round-table discussions. Nearly 20 IMPH Pears Foundation Alumni from Africa participated in the continuing education workshop and were exposed to advanced training in clinical trials design and management, geographic information systems, monitoring and evaluation, multi-level modeling, cost-utility analysis, and more. The topics were chosen based on the responses we received from a survey of the potential participants conducted prior to the workshop.

Within the framework of the workshop, a one-day symposium on "Health in Africa 2010" was hosted which brought together professionals, politicians, and students from Israel and abroad to discuss issues impacting 
on health and health care in Africa today - Health \& Health care in an Era of Economic Crisis, Food Security and Global Climate, and the Process and Challenges of Setting National Public Health Policy. This included a session on Africa-Israel ties, with participation from representatives of NGOs operating in Israel and in the Palestinian sector, and ambassadors from African countries. The feedback from the workshop and the symposium was very positive and we hope to implement this model with other groups of IMPH alumni in the future.

\section{OTHER TRAINING ACTIVITIES AT THE BRAUN SCHOOL}

Alongside our MPH training programs, we offer doctoral level training for Israeli and international post-graduate students. IMPH students who complete the degree with outstanding academic success are invited to compete for a very limited number of scholarships to support doctoral training at the Braun School. The research work must focus on a public health topic that is relevant to the doctoral candidate's own community, and rely on local data. The scholarship covers the cost of the data collection and allows the candidate to spend time at the Braun School enrolled in required $\mathrm{PhD}$ courses and gain experience in teaching MPH courses. To date, three IMPH graduates have enrolled in the Milstein PhD Scholarship Program one from Albania who completed his $\mathrm{PhD}$ degree on the effect of rapid social transition and dietary change on coronary heart disease in Albania, ${ }^{17,18}$ one from Colombia who completed her dissertation on transitions in the stages of drug use among a cohort of school-children in Bogota, ${ }^{19,20}$ and one from Russia who is expected to soon complete his dissertation on the contribution of alcohol to motor vehicle accident injuries and mortality in Russia.

As a WHO Collaborating Centre for Capacity Building in Public Health, we regularly carry out on-site short-term training workshops on various health topics (e.g., HIV/AIDS prevention, community-oriented primary care, health behavior, advanced research methods). In 2008, for example, two Braun faculty members ran a two-week seminar in Kumasi, Ghana on the topic of "Prevention and management of lifestyle related diseases through cultural adaptation" for 25 health professionals who worked on projects concerning nutrition, smoking prevention, hypertension screening and environmental health. We also host international workshops in Israel such as a bilateral workshop on Migrant Health that was organized in response to a request from the Open Health Institute of Moscow. The workshop was attended by 20 Russian participants from government, 
research institutes and NGOs, and numerous Israeli professionals from academia, the Ministry of Health and other ministries, as well as NGOs involved with migrants.

Braun School faculty members participated in annual "Summer Schools in Public Health" in Moscow, Tver, and Chelyabinsk, Russia from 2001 until 2005. These Summer Schools brought together Braun faculty members, IMPH graduates, and public health academics and local public health leaders from Russia and other countries in Central and Eastern Europe (CEE) and the Central Asian Region (CAR).

Our School of Public Health has also been very active, in collaboration with ASPHER, in promoting and consulting on post-graduate public health education in a number of countries in Africa, and particularly in former Soviet Countries of CEE, CAR, Russia and the Commonwealth of Independent States (CIS). Along with representatives of ASPHER and other international agencies, and with work done onsite, three conferences were conducted in Jerusalem in 2001-2002 for some 150 key persons from Russia, and many from CEE/CIS/CAR countries on developing new schools of public health. The Proceedings of the 2002 conference was published in a special edition of Public Health Reviews and distributed to all schools of public health in Europe, including Russia, and CEE/CAR. ${ }^{21}$

Since 2001, we have hosted a number of short-training courses in Jerusalem for health-professionals from developing and transition countries. The main objective of these "Visiting Faculty Programs" (VFPs) is to familiarize mid- and senior-level faculty and managerial personnel from countries that are developing new schools of public health with the culture, content and teaching methods of public health in a western country and in a school with longstanding and strong international experience. These VFPs provide local leaders with career development oriented training and capacity-building in public health policy, and have promoted deepening relations between the Braun School and newly developing schools of public health. Together with our graduates, some Braun faculty members have been instrumental in establishing and mentoring schools of public health and public health training programs in several Eastern European countries (e.g., Albania, Macedonia, Moldova, Russia), and the Palestinian Authority. These initiatives have resulted in the publication of an international textbook of Public Health authored by a member of the Braun faculty, with a Russian colleague. ${ }^{22}$ This is now the standard textbook of public health in the Russian language and is currently used throughout Russia. The book has also been translated into Albanian, Bulgarian, English, Georgian, Macedonian, Mongolian, Moldovan, Romanian, and Uzbek. 


\section{ISRAELI-ARAB PUBLIC HEALTH COOPERATION}

In keeping with the dictum that disease and health know no geopolitical boundaries, we are dedicated to developing and strengthening scientific and training collaboration with our Arab neighbors. Over the years, more than 30 Palestinian physicians and nurses have trained in our IMPH Program, some of whom now teach public health in the Al Quds University. Moreover, many of our IMPH graduates hail from non-Arab Muslim countries. Several senior Braun faculty members have ongoing collaborative scientific research projects with Palestinian researchers. Examples of such scientific collaboration include an extensive investigation of childhood lead exposure in the Palestinian Authority, Israel, and Jordan, a cooperative project on leishmaniasis in Israel and the West Bank which is a multidisciplinary, long-term, comprehensive collaborative study linking Hebrew University and Al-Quds researchers with colleagues from Egypt, Jordan, Morocco and Tunisia, investigation of coronary heart disease and its outcomes among adult Arabs in East Jerusalem, growth patterns of Palestinian children, and community-based dental health promotion and caries prevention programs among Arab children in East Jerusalem and in Bedouin communities in the southern region of Israel.

These many initiatives led to a joint project between the Braun School and the School of Public Health at Al Quds University that was formally established in 1999 to enhance collaboration in public health for the benefit of both constituencies and for developing a civil society infrastructure for peace and co-existence. The project faltered when the "intifada" broke out, although some joint work continued (e.g., co-tutoring of graduate students, joint workshops). Recently, representatives of both institutions re-established dialogue with the aim of reviving the project and initiating joint research and training in non-infectious diseases, environmental health, reproductive/mother-and-child health, and health promotion.

\section{CONCLUSION}

Israel is a young nation that has transitioned into a developed industrialized country despite a national agenda dominated by the challenges associated with absorption of immigrants from around the globe and ongoing threats to its security. The enormous efforts made in health promotion and disease prevention have resulted in lowering infant mortality seven to tenfold among Arabs and Jews, and life expectancy for Israeli males is among the highest for OECD countries. We have not forgotten that we reached our 
level of development as a result of help received, and it's our obligation to pass on the help and the know-how. At the Hebrew University-Hadassah Braun School of Public Health and Community Medicine, we continue to strengthen the global public health workforce through our IMPH Program and our other training activities and by fostering partnerships with academic and clinical institutions worldwide.

\section{Acronyms List}

ASPHER $=$ The Association of Schools of Public Health in the European Region

$\mathrm{CAR}=$ Central Asian Region

$\mathrm{CEE}=$ Central and Eastern European

CIS $=$ Commonwealth of Independent States

$\mathrm{COPC}=$ Community Oriented Primary Care

IMPH = International Master of Public Health

MASHAV $=$ The Israel Center for International Cooperation

MPH $=$ Master of Public Health

VFPs $=$ Visiting Faculty Programs

Conflicts of Interest: None declared.

\section{REFERENCES}

1. United Nations Department of Economic and Social Affairs. The Millennium Development Goals Report 2010. New York, NY: UN; 2010. Available from URL: http://www.un.org/millenniumgoals/pdf/MDG\%20Report\%20 2010\%20En\%20r15\%20-low\%20res\%2020100615\%20-pdf (Accessed 8 September, 2011).

2. Yu SM. Public health education and the world. Am J Public Health. 2008;98:1546.

3. Beaglehole R, Dal Poz MR. Public health workforce: challenges and policy issues. Hum Resour Health. 2003;1:4.

4. Purcell JM. Recruiting the future public health workforce: an analysis of prospect communication among accredited schools of public health. J Community Health. 2009;34:216-21.

5. Kahn K, Tollman SM. Planning professional education at schools of public health. Am J Public Health. 1992;82:1653-7.

6. Foldspang A.Association of Schools of Public Health in the European Region. Provisional lists of Public Health Core Competencies, European Public Health Core Competencies Programme (EPHCC) for Public Health Education, Phase 2. Brussels: ASPHER; 2008. Available from URL: http:// www.aspher.org/pliki/pdf/asphercompetenciesprogrammephase2report.pdf (Accessed 8 September, 2011).

7. Association of Schools of Public Health Education Committee. Master's Degree in Public Health Core Competency Model, version 2.3. Washington, DC: ASPH; 2006. Available from URL: http://www.asph.org/userfiles/version2.3.pdf (Accessed 8 September, 2011). 
8. Calhoun JG, Ramiah K, Weist EM, Shortell SM. Development of a core competency model for the master of public health degree. Am J Public Health. 2008;98:1598-607.

9. Abramson JH. Teaching epidemiology inside and outside the classroom. Public Health Rev. 2002;30:339-63.

10. Manor O. Teaching statistics in schools of public health. Public Health Rev. 2002;30:209-15.

11. Neumark Y, Friedlander Y. Training in survey and research methods within a master of public health program. Public Health Rev. 2002;30:217-29.

12. Paltiel O, Brezis M, Lahad A. Principles for planning the teaching of evidencebased medicine/clinical epidemiology for MPH and medical students. Public Health Rev. 2002;30:261-70.

13. Epstein L, Gofin J, Gofin R, Neumark Y. The Jerusalem experience: three decades of service, research and training in community-oriented primary care. Am J Public Health. 2002;92:1717-20.

14. Gofin J. Planning the teaching of community health (COPC) in an MPH program. Public Health Rev. 2002;30:293-301.

15. Williams RL. Motherhood, apple pie, and COPC. Ann Fam Med. 2004;2:100-2.

16. Gordon LJ, McFarlane DR. Public health practitioner incubation plight: following the money trail. J Public Health Policy. 1996;17:59-70.

17. Burazeri G, Kark JD. Moderate alcohol intake, though not regular heavy drinking, is protective for acute coronary syndrome: a population-based, case-control study in southeast Europe. Ann Epidemiol. 2011;21:564-71.

18. Burazeri G, Kark JD. Negative attitudes to transition in post-communist Albania and acute coronary syndrome. Health Psychol. 2009;28:779-86.

19. Lopez-Quintero C, Neumark Y. Volatile substance misuse among Bogotá school children. Substance Use Misuse. 2011;46:50-6.

20. Lopez-Quintero C, Neumark Y. Effects of risk perception of marijuana use on marijuana use and intentions to use among adolescents in Bogotá, Colombia, Drug Alcohol Depend, 2010;109:65-72.

21. Tulchinsky TH, Epstein L, Normand C (Editors). Developing new schools of public health in countries of Eastern Europe and the newly independent states. Public Health Rev. 2002;30(1-4):1-295.

22. Tulchinsky TH, Varavikova EA. The new public health, second edition. San Diego, CA: Academic Press/Elsevier; 2009. 